\title{
Renal function in patients undergoing cardiopulmonary bypass for open cardiac surgical procedures.
}

\author{
Irshad Ahmad', *Mubasher Ahmad Bhat ${ }^{2}$, Abdul Wahid Bhat ${ }^{3}$,Mohamad Ommid", Tanveera Gani', \\ Gousia Nisa ${ }^{5}$ \\ Assistant Professor ${ }^{1}$, Senior Resident ${ }^{2}$, Lecturer ${ }^{4}$ Department of Anaesthesiology and Critical care, Assistant \\ Professor ${ }^{3}$ Department of Blood Transfusion and Immunohematology, Sher-i-Kashmir Institute of Medical \\ Sciences and Medical College, Srinagar, India. Assistant Surgeon ${ }^{5}$, Department of Health Services, Jammu and \\ Kashmir, India.
}

\section{*Corresponding author: ahmadmubashir84@yahoo.com}

\begin{abstract}
Background:
Renal dysfunction following cardiopulmonary bypass is a frequent complication of open heart surgery. Acute renal failure requiring dialysis occurs in approximately $1.5 \%$ of patients following cardiac surgery and remains a cause of major morbidity and mortality.
\end{abstract}

\begin{abstract}
Method:
Sixty-five patients of either sex in the age group of $10-50$ years scheduled to undergo various cardiac procedures were included in this study. All patients had normal preoperative levels of serum creatinine, blood urea nitrogen, blood glucose levels, urine analysis, 24 hour urinary protein $<200 \mathrm{mg}$, and normal 24 hour creatinine clearance. After surgery, patients were transferred to an intensive care unit for postoperative management and monitoring. Patients were shifted to cardiovascular and thoracic surgery ward as soon as their clinical condition permitted. Blood urea nitrogen, serum creatinine, 24 hour creatinine clearance was performed on day one and day seven of postoperative period.
\end{abstract}

Result:

Postoperative oliguric acute renal failure was $7.7 \%$ and overall mortality was $6.1 \%$. We found no association between aortic cross clamp time and postoperative renal dysfunction.

\section{Conclusion:}

Optimisation of cardiac performance post cardiopulmonary bypass seems to be the most important factor in the prevention of postoperative renal dysfunction in patients requiring total cardiopulmonary bypass.

Key words: Cardiopulmonary bypass, acute renal failure, aortic cross clamp time

\section{Introduction}

Cardiopulmonary bypass (CPB) allows perfusion of the patient's vital organs while oxygenating blood and removing carbon dioxide permitting surgical exposure of heart and great vessels. Most cardiac procedures use full cardiopulmonary bypass, in which blood is drained from right side of heart and returned to systemic circulation through the aorta. The cardiopulmonary bypass circuit performs functions of both heart and lungs ${ }^{1}$.

Renal dysfunction following CPB is a frequent complication of open heart surgery. Acute renal failure (ARF) requiring dialysis occurs in approximately $1.5 \%$ of patients following cardiac surgery and remains a cause of major morbidity and mortality ${ }^{2}$. Impairment of renal function (plasma creatinine levels greater than $1.5 \mathrm{mg} / \mathrm{dl}$ but less than $5 \mathrm{mg} / \mathrm{dl}$ ) occurs after $30 \%$ of cardiac operations performed with CPB and is associated with a mortality rate of 7-38 \% ${ }^{3}$. When acute renal failure after CPB is severe enough to require dialysis morality reaches 70 $100 \%{ }^{4}$. This is in marked contrast to the $1-2 \%$ mortality rate observed in patients whose cardiac operation is not complicated by acute renal failure ${ }^{4}$.

The negative effect of $\mathrm{CPB}$ on renal function may be due to several factors including non pulsatile blood flow, inadequate renal perfusion and free plasma haemoglobin $5,6,7,8$. 
The aetiology of renal insufficiency following cardiac surgery is poorly understood but it is believed that ischaemic injury of the kidney resulting from inadequate perfusion is a major factor, although renal injury by exotoxins (e.g. antibiotics, anaesthetic agents, contrast media, diuretics etc.) and endotoxins (e.g. myoglobin) may also be involved ${ }^{9}$. Cardiopulmonary bypass utilizing non-pulsatile flow produces alteration in vasomotor tone with initial vasodilatation and subsequent vasoconstriction. This vasomotor response to bypass ultimately produces renal arteriolar vasoconstriction with resultant reduction in renal and cortical blood flow and potential development of renal tubular necrosis. Angiotensin II levels are reported to be higher during nonpulsatile CPB. These elevations in angiotensin II could contribute to renal vasoconstriction ${ }^{8}$.

Among other factors, $\mathrm{CPB}$ is incriminated in pathogenesis of renal failure since such intraoperative factors such as prolonged duration of cardiopulmonary bypass, haemoglobinemia, hypotension, oliguria and low output syndromes have been shown to correlate with development of renal failure ${ }^{10,11,12}$.

This prospective study was undertaken to study renal function in patients undergoing cardiopulmonary bypass for open cardiac procedures.

\section{Methods}

This study was conducted in department of anaesthesiology and critical care over a two year period. After approval from the institutional ethical committee and informed consent, 65 patients of either sex in the age group of $10-50$ years scheduled to undergo various cardiac procedures were enrolled in the study. Inclusion criteria were represented by normal preoperative levels of serum creatinine, blood urea nitrogen (BUN), blood glucose levels, urine analysis, 24 hour urinary protein $<200 \mathrm{mg}$, and normal 24 hour creatinine clearance. Patients with any degree of renal impairment and those with diabetes mellitus were excluded from this study. After pre-operative evaluation patients underwent elective cardiac surgical procedures with CPB. Induction of anaesthesia with propofol $3 \mathrm{mg} / \mathrm{kg}$, atracurium $0.5 \mathrm{mg} / \mathrm{kg}$ and morphine $100 \mu \mathrm{g} / \mathrm{kg}$ was followed by maintenance with nitrous oxide $66 \%$ in oxygen and intermittent halothane $0.5-1 \%$ and/or midazolam $0.05 \mathrm{mg} / \mathrm{kg}$ in incremental doses with atracurium $100 \mu \mathrm{g} / \mathrm{kg}$ based on neuromuscular monitoring done by train of four stimulation.

Monitoring included invasive arterial and central venous cannulation with a temperature probe placed in lower third of oesophagus to monitor core temperature.

The surgical technique consisted of median sternotomy and cannulation of aorta, superior vena cava and inferior vena cave. Cardiopulmonary bypass (CPB) was employed at moderate systemic hypothermia $\left(28-32^{\circ} \mathrm{C}\right)$ and at moderate haemodilution. Continuous normothermic blood cardioplegia was administered either through aortic root or coronary sinus to provide myocardial protection during an aortic cross clamping period. During this procedure besides the above parameters, urine output, arterial blood gaseous status and serum electrolytes were monitored before CPB, during and immediately after CPB.

After completion of procedure patients were transferred to surgical intensive care unit for postoperative management and monitoring. Patients were managed with or without ventilatory or inotropic support depending on their clinical condition. Patients were shifted to cardiovascular and thoracic surgery ward as soon as their clinical condition permitted. Blood urea nitrogen, serum creatinine, 24 hour creatinine clearance was performed on day one and day seven of postoperative period.

Statistical analysis was performed on SSPS version 11.3, statistical software for social sciences, Chicago, U.S.A for windows and included students paired t-test and ANOVA. A p value $<0.05$ was considered significant.

\section{Results}

A total of 65 patients who underwent cardiopulmonary bypass for open cardiac surgical procedures were studied for comparision of their renal functions preoperatively and postoperatively. Maximum number of patients $(\mathrm{n}=20)$ were in the age group of $30-39(30.7 \%)$ with an approximate male to female ratio of $1: 1$. The surgical procedures performed on study patients were Mitral valve replacement(MVR), Atrial septal defect(ASD)repair, Aortic valve replacement(AVR), Double valve 
replacement(DVR) and Left atrial myxoma(LAM) excision. (Table 1).

Table 1: Surgical procedures

\begin{tabular}{ll}
\hline Surgical Procedures & No. of patients \\
\hline Mitral valve replacement & 24 \\
Atrial septal defect repair & 22 \\
Double valve replacement & 9 \\
& \\
Aortic valve replacement & 8 \\
Left atrial myxoma excision & 2 \\
Total & 65 \\
\hline
\end{tabular}

Table 2: Showing total cardiopulmonary bypass time (in minutes) in relation to various surgical procedures

Mean $\pm \mathrm{SD}=$ Mean Standard Deviation

\begin{tabular}{ll}
\hline $\begin{array}{l}\text { Surgical } \\
\text { procedures }\end{array}$ & $\begin{array}{l}\text { Total cardiopulmonary } \\
\text { bypass (CPB) } \\
\text { time (mins) (Mean } \pm \text { SD) }\end{array}$ \\
\hline $\begin{array}{l}\text { Double valve } \\
\text { replacement }\end{array}$ & $143.33 \pm 8.83$ \\
$\begin{array}{l}\text { Aortic valve } \\
\text { replacement }\end{array}$ & $101.38 \pm 16.78$ \\
$\begin{array}{l}\text { Mitral valve } \\
\text { replacement }\end{array}$ & $95.67 \pm 9.36$ \\
$\begin{array}{l}\text { Left atrial myxoma } \\
\text { excision }\end{array}$ & $64.00 \pm 2.83$ \\
Atrial septal defect & $57.86 \pm 6.82$ \\
Repair & \\
\hline
\end{tabular}

The total cardiopulmonary bypass time and aortic cross clamp time was maximum for patients who underwent DVR Mean \pm SD $143.33 \pm 8.83$ and $74.44 \pm 4.25$ followed by AVR Mean \pm SD $\quad 101.38 \pm 16.78$ and $52.13 \pm 11.53$ respectively. (Table 2 and 3 ).
Table 3: Showing aortic cross clamp time (in minutes) in relation to various surgical procedures

Mean $\pm \mathrm{SD}=$ Mean Standard Deviation

\begin{tabular}{ll}
\hline Surgical procedures & $\begin{array}{l}\text { Aortic Cross Clamp } \\
\text { (ACCT) } \\
\text { time (minutes) } \\
\text { (Mean } \pm \text { SD) }\end{array}$ \\
\hline Double valve replacement & $74.44 \pm 4.25$ \\
Aortic valve replacement & $52.13 \pm 11.53$ \\
Mitral valve replacement & $50.17 \pm 4.82$ \\
Left atrial myxoma & $35.50 \pm 3.54$ \\
excision & \\
Atrial septal defect repair & $30.27 \pm 5.61$ \\
\hline
\end{tabular}

Deranged kidney function tests on postoperative day 7 was observed in $8.3 \%$ of patients who underwent MVR,22.2\% of patients who underwent DVR and $12.5 \%$ of patients who underwent AVR. (Table 4).

Table 4: Showing percentage of patients with renal dysfunction (deranged KFT's) in relation to surgical procedures.

\begin{tabular}{llll}
\hline $\begin{array}{l}\text { Surgical } \\
\text { Procedures }\end{array}$ & $\begin{array}{l}\text { Total } \\
\text { Number } \\
\text { of } \\
\text { patients }\end{array}$ & $\begin{array}{l}\text { Total } \\
\text { Number } \\
\text { patients } \\
\text { with } \\
\text { deranged } \\
\text { KFT }\end{array}$ & Percentage \\
\hline $\begin{array}{l}\text { Mitral valve } \\
\text { replacement }\end{array}$ & 24 & 2 & 8.3 \\
$\begin{array}{l}\text { Atrial septal } \\
\text { defect repair } \\
\text { Double valve }\end{array}$ & 22 & None & 0 \\
$\begin{array}{l}\text { replacement } \\
\text { Aortic valve } \\
\text { replacement }\end{array}$ & 8 & 2 & 22.2 \\
$\begin{array}{l}\text { Left atrial } \\
\text { myxoma excision }\end{array}$ & 2 & 1 & 12.5 \\
\hline
\end{tabular}

Blood urea nitrogen, serum creatinine and 24 hour creatinine clearence values were taken preoperatively, postoperatively on day 1 and postoperatively day 7 and compared among the studied patients. A statistically significant difference was found while comparing postoperative day 1 with postoperative day 7

BUN in patients who underwent MVR and a statistically significant difference was found while comparing preoperative with postoperative day 1 BUN in patients who underwent ASD repair. (Figure 1). 

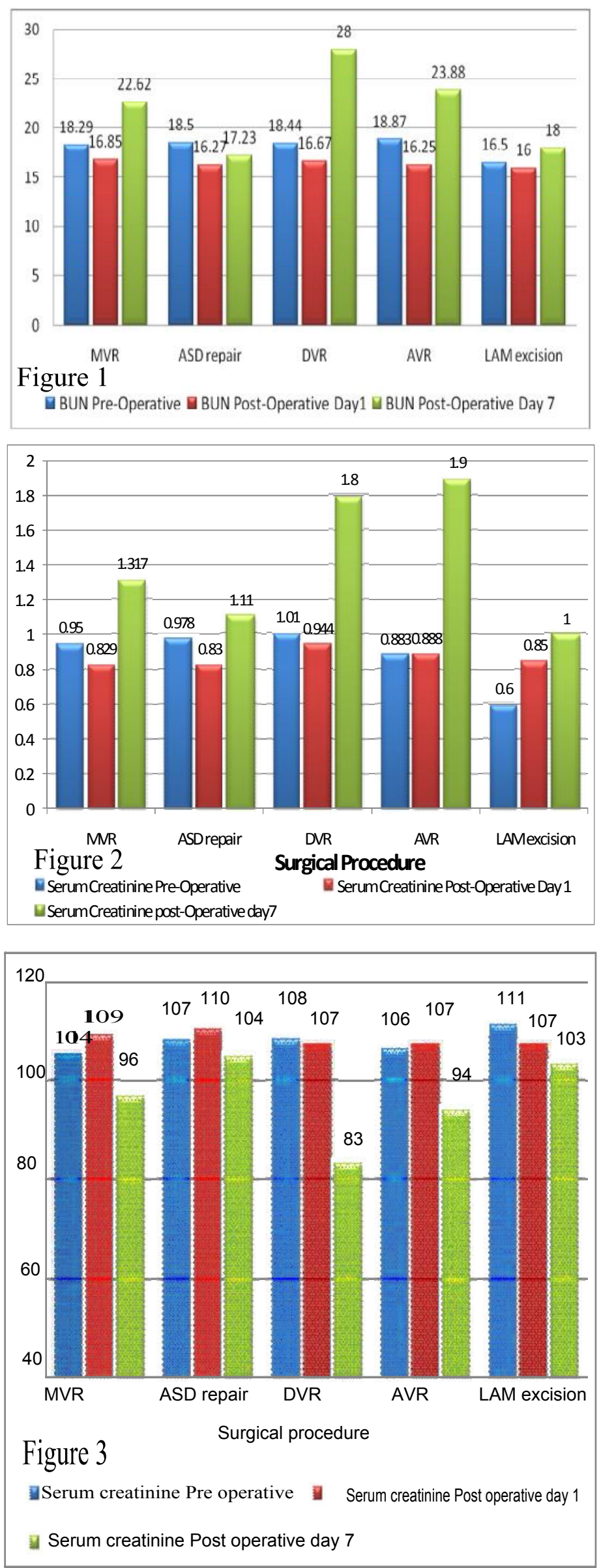

For serum creatinine and 24 hour creatinine clearence values, while comparing preoperative with postoperative day 7 and postoperative day 1 with postoperative day 7 , a statistically significant difference was observed in MVR, AVR and ASD repair patients. (Figure 2 and 3).

\section{DISCUSSION}

The development of acute kidney injury (AKI) after adult cardiac surgery is associated with increased morbidity and mortality ${ }^{13}$. The morbidity was $7.69 \%$

due to postoperative oliguric acute renal failure and the overall mortality was $6.1 \%$ in our study.

The development of acute postoperative renal insufficiency after cardiac operations has been attributed to cardiopulmonary bypass as a result of haemodynamic factors or toxic insults on the kidneys or both ${ }^{4}$.

In our study procedures involved ranged from congenital defects to valve replacements. Commonest procedure performed was mitral valve replacement (MVR) followed by ASD repair.

In our results the patient with maximal total cardiopulmonary bypass (CPB) time (160 minutes) had a normal postoperative course. Patients who had postoperative deranged kidney function tests had total CPB times lower than some of the patients who had a normal postoperative course. This is in accordance with the study by Mancini $\mathrm{E}$ et $\mathrm{al}^{14}$ which revealed that CPB time did not predict acute renal failure during cardiac surgery. Moghissi and co-workers confirmed that there is reduction in renal blood flow after two hours of CPB possibly causing renal dysfunction which was in contradiction to our study ${ }^{7}$. The reason of contradiction with Moghissi $\mathrm{K}$ et al study is likely to be by the use of Para amino Hippuric acid (PAH) clearance technique used for that study as the kidneys may store PAH and 
later

release it. So, on long perfusions tubular cells may become less functional in extracting PAH inspite of full blood flow. Safe duration of total CPB is thought to be closer to three hours in general ${ }^{16}$. It has been suggested more specifically that postoperative renal dysfunction is due to renal afferent arteriolar vasoconstriction during CPB. Although in terms of renal blood flow there are no really gross differences between pulsatile and non-pulsatile $\mathrm{CPB}^{6,17}$.

In our study there was no correlation between aortic cross clamp time (ACCT) and postoperative renal dysfunction. Minimum ACCT was 18 minutes for ASD repair and maximum ACCT was 83 minutes for DVR. Patients who had postoperative deranged kidney function had ACCT lower than some of those patients who had a normal postoperative course. Estimate of safe ACCT during CPB is not valid due to differing vulnerabilities between patients 1 .

The morbidity of $7.69 \%$ due to postoperative oliguric acute renal failure (ARF) and the overall mortality of $6.1 \%$ in our study are significantly lower than a study done by Gailiunas P Jr et al ${ }^{3}$. In our study ARF requiring dialysis occurred in $100 \%$ of patients and there was mortality of $80 \%$ which is in agreement with the study by Hieberman $\mathrm{L}$ et $\mathrm{al}^{4}$. However, the patients in our study were in age group of 10-50 years and had normal pre-operative renal function tests. It is still controversial whether age is important in predisposing to ARF though a reduced functional capacity of kidneys is documented in older patients ${ }^{18}$.

Blood urea nitrogen, serum creatinine and 24hour creatinine clearance were utilised as indicators of renal function. For patients who underwent MVR $(n=24)$ comparison of BUN on postoperative day 7 with BUN postoperative dayl showed statistically significant difference. For patients who underwent ASD repair, there was a decrease in BUN on postoperative day 1 with respect to pre-operative values and the difference was statistically significant. This lower BUN on postoperative day 1 is possibly because of atrial natriuretic peptide (ANP) release during manipulation of atria ${ }^{19}$. When considering patients who underwent DVR $(\mathrm{n}=9)$ and AVR $(n=8), 2$ patients with DVR and one patient with AVR had very high BUN on postoperative day 7 with respect to pre-operative values leading to higher standard deviation ( \pm 19.22 in case of DVR and \pm 15.98 in case of AVR). Hence statistical significance was not observed.

A decrease in serum creatinine was found on postoperative day 1 with respect to pre-operative values in patients undergoing various surgical procedures except in case of AVR patients. In MVR, ASD repair and AVR patients, a statistically significant difference was found between serum creatinine (pre-operative, postoperative day 1 and postoperative day 7). Patients who underwent DVR ( $n=9,2$ patients of DVR) had very high serum creatinine on postoperative day 7 with respect to postoperative day 1 and pre-operative values leading to higher standard deviation $( \pm 1.40)$. Hence statistical significance was not observed.

There was an increase in 24hour creatinine clearance on postoperative day 1 in comparison with pre-operative values for patients undergoing various surgical procedures except for DVR and LAM excision. In MVR and ASD repair a statistically significant difference was found between 24 hour creatinine clearance (preoperative, postoperative day 1 and postoperative day 7). Patients who underwent DVR $(n=9)$ and $\operatorname{AVR}(n=8), 2$ patients of DVR and one patient of AVR had significant decrease in 24hour creatinine clearance on postoperative day 7 with respect to pre-operative values leading to higher standard deviation $( \pm 35.81$ in case of DVR and \pm 25.94 in case of AVR). Hence statistical significant difference could not be achieved. The results in our study are in agreement with the study by Mancini E et al ${ }^{14}$.

The intraoperative urinary output has been taken into consideration only in a minority of the studies on ARF after cardiac operation. Abel and colleagues ${ }^{11}$ registered a lower diuresis before $\mathrm{CPB}$ in patients with postoperative renal impairment, whereas urinary output during and after CPB was not different. Slogoff and associates $^{20}$ evaluated the incidence of oliguria during $\mathrm{CPB}$, and Crown and associates ${ }^{21}$ considered the total intraoperative diuresis. Both studies failed to demonstrate any statistical correlation with postoperative renal outcome. In our study all patients who underwent CPB for open cardiac surgical procedures received diuretic treatment with furosemide during CPB 
and patients who underwent valvular replacements received additional mannitol during $\mathrm{CPB}$, thereby proving that intraoperative diuresis has no correlation with postoperative renal outcome.

In the study by Parolari A et $\mathrm{al}^{23}$ ARF occurred in $8.9 \%$ patients with pre-operative normal renal function tests. In contrast in our study postoperative oliguric ARF occurred in $7.69 \%$. This difference may be because of the large sample size in the study by Parolari A et $\mathrm{al}^{13}$. In our study all patients with ARF received dialysis, overall mortality in our study was $6.1 \%$ and mortality in patients requiring dialysis was $80 \%$.

\section{CONCLUSION}

The prevention of acute renal failure in the cardiovascular surgical patients appears to be still the major challenge. Despite the use of physical and pharmacological adjuncts for its prevention and monitoring of haemodynamic variables, the incidence of postoperative renal failure has not decreased in patients who had normal pre-operative renal status. Optimisation of cardiac performance post cardiopulmonary bypass seems to be the most important observed factor in the prevention of postoperative renal dysfunction in patients requiring total cardiopulmonary bypass.

\section{References}

1. James A. Dinardo .Management of cardiopulmonary bypass: Anaesthesia for cardiac surgery (2nd edition); Appleton and Lange, Stamford Connecticut; 277-320.

2. Conlon PJ, Stafford Smith M, White WD, Newman MF, King S, Winn MP, Landolf K. Acute renal failure following cardiac surgery.

3. Nephrol Dial Transplant 1999; 14(11):158162.

4. Gailiunas P Jr, Chawla R, Lazarus JM, Chon

L, Saundes J, Merrill JP. Acute renal failure

following cardiac operations. J Thorac

Cardiovasc Surgery 1980; 79:241-243.

PMid: 7351847

5. Hilberman L, Derby GC, Spencer RJ, Stinson EB. Sequential pathophysiological changes characterising the progression from renal dysfunction to acute renal failure following cardiac operations. J Thorac Cardiovasc Surg
1980; 79:838-844.

PMid:7374199

6. Mandelbaum I, Burns WH. Pulsatile and non pulsatile blood flow. JAMA 1965; 191:657-660. http://dx.doi.org/10.1001/jama.1965.030800800 47013

PMid:14242425

7. Porte GA, Kloster FE, Herr RJ, et al. Relationship between alterations in renal haemodynamics during cardiopulmonary bypass and postoperative renal function. Circulation 1966; 34:1005-1021.

http://dx.doi.org/10.1161/01.CIR.34.6.1005

8. Moghissi K, Maclell ES, Munday KA.

Changes in renal blood and PAH extraction

during extracorporeal circulation of short and

long duration. Cardiovasc Res 1969; 3:37-44.

http://dx.doi.org/10.1093/cvr/3.1.37

PMid:5357765

9. Watkins L Jr, Lucas SK, Gardner TJ, et al. Angiotensin II levels during cardiopulmonary

bypass; a comparison of pulsatile and nonpulsatile flow. Surg Forum 1979; 30; 229.

PMid: 161427

10. Osborne JJ, Cohn K, Hait M, et al.

Hemolysis during perfusion. Sources and means of reduction. J Thorac Cardiovasc Surg 1962;43:459-464

11. Yeboah ED, Petric A, Pead JL. Acute renal failure and open heart surgery. Br Med J 1972; 1:415-18.

http://dx.doi.org/10.1136/bmj.1.5797.415

PMid:5058160 PMCid:1787356

12. Abel RM, Buckley MJ, Austen WG, Barnet GO, Beck CH, Fischer JE. Etiology, incidence and prognosis of renal failure following cardiac operation: results of a postoperative analysis of 500 consecutive patients. J Thorac Cardiovasc Surg 1976; 71:323-333.

PMid: 1249963

13. Bhat JG, Gluck MC, Lowenstein J, Baldwin DS. Renal failure after open heart surgery. Ann Intern Med 1976; 84:677-682 PMid:937879

14. Parolari A, Pesce LL, Pacini D, Mazzanti V, Salis S, Sciacovelli C, Rossi F, Alamanni F; Monzino Research Group on Cardiac Surgery Outcomes. Risk factors for perioperative acute kidney injury after adult cardiac surgery: role of perioperative management. Ann Thorac

Surg.2012;93(2):584-91 http://dx.doi.org/10.1016/j.athoracsur.2011.09.0 $\underline{73}$ 
PMid:22269725

15. Mancini E, Caramelli F, Ranucci M, Sangiorgi D, Reggiani LB, Frascaroli G, Zucchelli A, Bellasi A, Santoro A. Is time on cardiopulmonary bypass during cardiac surgery associated with acute kidney injury requiring dialysis?. Hemodial Int.2011 Apr;16(2):252-8 http://dx.doi.org/10.1111/j.15424758.2011.00617.x

PMid:22099028

16. Endre ZH. Post cardiac surgery acute renal failure in the 1990's. Aust NZ J Med 1997; 25:278-79.

http://dx.doi.org/10.1111/j.14455994.1995.tb01889.x

17. Kouchoukos NT, Blackstone EH, Doty DS, Hanley FL,Karp RB (eds): Cardiac surgery (3rd edition); Hypothermic circulatory arrest and cardiopulmonary bypass; safe duration of CPB :103-105.

18. Boucher JK, Rudy LW, Enmunds LH Jr. Organ blood flow during pulsatile cardiopulmonary bypass. J Appl Physiol 1974;36:86.

PMid:4203754

19. Philbin DM, Levine FH, Kono K,et al.Attenuation of the stress response to cardiopulmonary bypass by the addition of pulsatile flow. Circulation 1981;64:808.

http://dx.doi.org/10.1161/01.CIR.64.4.808 PMid:7023745

20. William F. Ganong. Endocrine functions of the kidneys, heart and pineal gland: Review of medical physiology (19th edition);Appleton and Lange:439-441.

21. Slogoff S, Reul GJ, Keats AS et al. Role of perfusion pressure flow in major organ dysfunction after cardiopulmonary bypass. Ann Thorac Surg 1990; 50:911-918. http://dx.doi.org/10.1016/0003-4975(90)91118$\mathrm{U}$

22. Corwin HL, Sprague SM, DeLaria GA, et Al. Acute renal failure associated with cardiac operation, a case control study. J Thorac Cardiovasc Surg 1989;98:1107-1112. PMid:2586128 